\title{
Targeted 'Next-Generation' sequencing in anophthalmia and microphthalmia patients confirms SOX2, OTX2 and FOXE3 mutations
}

\author{
Nelson Lopez Jimenez ${ }^{1}$, Jason Flannick², Mani Yahyavi ${ }^{1}$, Jiang Li ${ }^{3}$, Tanya Bardakjian ${ }^{4}$ Leath Tonkin,
} Adele Schneider ${ }^{4}$, Elliott $H$ Sherr $^{3}$ and Anne M Slavotinek ${ }^{1 *}$

\begin{abstract}
Background: Anophthalmia/microphthalmia (A/M) is caused by mutations in several different transcription factors, but mutations in each causative gene are relatively rare, emphasizing the need for a testing approach that screens multiple genes simultaneously. We used next-generation sequencing to screen $15 \mathrm{~A} / \mathrm{M}$ patients for mutations in 9 pathogenic genes to evaluate this technology for screening in A/M.

Methods: We used a pooled sequencing design, together with custom single nucleotide polymorphism (SNP) calling software. We verified predicted sequence alterations using Sanger sequencing.

Results: We verified three mutations - C.542delC in SOX2, resulting in p.Pro181Argfs*22, p.Glu105X in OTX2 and p. Cys240X in FOXE3. We found several novel sequence alterations and SNPs that were likely to be non-pathogenic p.Glu42Lys in CRYBA4, p.Val201Met in FOXE3 and p.Asp291Asn in VSX2. Our analysis methodology gave one false positive result comprising a mutation in PAX6 (c.1268A > T, predicting p.X423Leuext $\left.X^{*} 15\right)$ that was not verified by Sanger sequencing. We also failed to detect one 20 base pair (bp) deletion and one 3 bp duplication in SOX2.

Conclusions: Our results demonstrated the power of next-generation sequencing with pooled sample groups for the rapid screening of candidate genes for $\mathrm{A} / \mathrm{M}$ as we were correctly able to identify disease-causing mutations. However, next-generation sequencing was less useful for small, intragenic deletions and duplications. We did not find mutations in 10/15 patients and conclude that there is a need for further gene discovery in A/M.
\end{abstract}

Keywords: anophthalmia, microphthalmia, next-generation sequencing, SOX2, OTX2, FOXE3

\section{Background}

Anophthalmia is found in 1 in 5,000 to 10,000 individuals and is a devastating birth defect because of severe visual impairment [1]. Genetic testing to identify the cause of anophthalmia and/or microphthalmia (A/M) is frequently requested. The transcription factor $S O X 2$ is mutated in $10-20 \%$ of patients with bilateral $\mathrm{A} / \mathrm{M}$ and genomic sequencing and deletion analysis of this gene is the first test to determine the cause of severe bilateral $\mathrm{A} / \mathrm{M}[2,3]$. However, the remaining pathogenic genes implicated in A/M, such as OTX2 or GDF6, are each mutated in a small percentage of patients and more

\footnotetext{
*Correspondence: slavotia@peds.ucsf.edu

'Department of Pediatrics, Division of Genetics, University of California, San Francisco, 533 Parnassus St, Room U585P, San Francisco CA 94143-0748 USA Full list of author information is available at the end of the article
}

than $60 \%$ of patients with $\mathrm{A} / \mathrm{M}$ do not receive a molecular diagnosis after currently available clinical genetic testing (Table 1) [4-16]. In addition, screening of all of the known $\mathrm{A} / \mathrm{M}$ genes is rarely completed on a clinical basis because there is no currently available panel that covers all of the known genes.

Next-generation sequencing is a recently developed, massively parallel, large-scale sequencing technology that has been used for rapid gene cloning and mutation detection [16]. Next-generation sequencing with exome selection was used to identify the causative genes for Miller syndrome and Kabuki syndrome and has identified mutations in genes for congenital chloride diarrhea and Fowler syndrome [17-20]. Next-generation sequencing has primarily been applied to Mendelian disorders in order to simplify analysis and few birth defects or

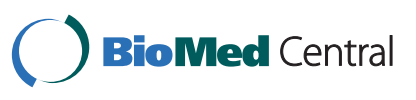


Table 1 Known Anophthalmia/Microphthalmia Genes Investigated by Next-Generation Sequencing

\begin{tabular}{|c|c|c|c|c|c|c|c|}
\hline Gene & Chromosome location & $\begin{array}{l}\text { NCBI Reference } \\
\text { Sequence (hg19) } \\
\text { mRNA }\end{array}$ & $\begin{array}{l}\text { Exon } \\
\text { count }\end{array}$ & $\begin{array}{l}\text { Coding exon } \\
\text { count }\end{array}$ & $\begin{array}{l}\text { Estimated } \\
\text { Mutation } \\
\text { Frequency } \\
\end{array}$ & $\begin{array}{l}\text { Inheritance } \\
\text { pattern }\end{array}$ & Reference \\
\hline SOX2 & $\begin{array}{l}\text { chr3:182912416- } \\
182914917\end{array}$ & NM_003106.2 & 1 & 1 & $10-20 \%$ & $\begin{array}{l}\text { Autosomal } \\
\text { dominant }\end{array}$ & 6,7 \\
\hline GDF6 & $\begin{array}{l}\text { chr8:97,223,734- } \\
97,242,196\end{array}$ & NM_001001557.2 & 3 & 3 & $8 \%$ & $\begin{array}{l}\text { Autosomal } \\
\text { dominant }\end{array}$ & 5 \\
\hline OTX2 & $\begin{array}{l}\text { chr14:56337178- } \\
56346937\end{array}$ & NM_021728.2 & 5 & 3 & $3.3 \%$ & $\begin{array}{l}\text { Autosomal } \\
\text { dominant }\end{array}$ & 8 \\
\hline VSX2 & $\begin{array}{l}\text { chr14:73775928- } \\
\text { 73799194 }\end{array}$ & NM_182894.2 & 5 & 5 & $2 \%$ & $\begin{array}{l}\text { Autosomal } \\
\text { dominant }\end{array}$ & 9 \\
\hline FOXE3 & chr1:47654331-47656311 & NM_012186.2 & 1 & 1 & Rare & $\begin{array}{l}\text { Autosomal } \\
\text { recessive/ } \\
\text { Autosomal } \\
\text { dominant }\end{array}$ & 10 \\
\hline CRYBA4 & $\begin{array}{l}\text { chr22:25347928- } \\
25356636\end{array}$ & NM_001886.2 & 6 & 5 & Rare & $\begin{array}{l}\text { Autosomal } \\
\text { Dominant }\end{array}$ & 11 \\
\hline PAX2 & $\begin{array}{l}\text { chr10:102495458- } \\
102579688\end{array}$ & NM_003990.3 & 11 & 11 & Rare & $\begin{array}{l}\text { Autosomal } \\
\text { dominant }\end{array}$ & 12 \\
\hline PAX6 & $\begin{array}{l}\text { chr11:31762916- } \\
31796085\end{array}$ & NM_000280.3 & 13 & 10 & Rare & $\begin{array}{l}\text { Autosomal } \\
\text { dominant }\end{array}$ & 13 \\
\hline SIX3 & chr2:45022541-45025894 & NM_005413.3 & 2 & 2 & Rare & $\begin{array}{l}\text { Autosomal } \\
\text { dominant }\end{array}$ & 14 \\
\hline BMP4 & $\begin{array}{l}\text { chr14:53486205- } \\
53491020\end{array}$ & NM_001202.3 & 4 & 2 & Rare & $\begin{array}{l}\text { Autosomal } \\
\text { dominant }\end{array}$ & 15 \\
\hline
\end{tabular}

malformations have been studied. We chose to use this technology to screen known candidate genes in 15 patients with $\mathrm{A} / \mathrm{M}$ in a pilot study to determine the efficacy of next-generation sequencing for the rapid screening of multiple genes in patient cohorts with birth defects.

\section{Methods}

Written informed consent and genomic DNA samples were obtained from 15 patients with A/M (Table 2) under an approved protocol for the Anophthalmia/ Microphthalmia Registry and gene-screening project (Institutional Review Board, Albert Einstein Medical Center). This research adhered to the tenets of the Declaration of Helsinki.

We divided the 15 patients into two separate groups (Table 2) for sequencing in individual lanes of a flow cell - ANOP1 (8 patients) and ANOP2 (7 patients). The patient samples in each group were pooled without barcoding. For ANOP1, we sequenced 9 known A/M genes (FOXE3, SIX3, SOX2, PAX2, PAX6, BMP4, OTX2, VSX2, and $C R Y B A 4$; gene order dictated by chromosome location). Our positive control was patient 09-122, who was known to have a $S O X 2$ mutation, c.542delC, predicting p.Pro181Argfs*22. For ANOP2, we added GDF6 so that 10 known A/M genes (FOXE3, SIX3, SOX2, GDF6, PAX2, PAX6, BMP4, OTX2, VSX2, and CRYBA4) were sequenced. Our positive control was patient 792-531, with a SOX2 sequence alteration, c.67-69dupGGC, resulting in the insertion of an additional glycine residue to the protein.

Primers for amplification of the coding regions were designed with Primer3 http://frodo.wi.mit.edu/primer3/ based on reference sequences from Entrez Gene http:// www.ncbi.nlm.nih.gov/gene. The primers used are provided in Additional File 1, Table S1. Polymerase chain reaction (PCR) products for each patient were pooled after estimating concentrations on an ethidium bromide-stained agarose gel and correlating with the size of the amplicon to obtain equal representation of all amplicons in the final mixture. Pooled DNA reactions were column purified (Qiagen, Valencia, CA) and libraries were prepared for sequencing on the Illumina genome analyzer (GA) platform (Illumina, San Diego, CA). We used 32-bp, paired-end reads and the standard sequencing primer (Illumina, San Diego, CA). After library construction, quality was checked using a DNA chip (2100 Bioanalyzer; Agilent Technologies, Santa Clara, CA). The libraries were sequenced at the Vincent J. Coates Genomics Sequencing Laboratory, California Institute for Quantitative Biosciences http://qb3.berkeley.edu/gsl/Home.html. Image analysis and base calling was performed by Illumina pipeline version 1.4 with default parameters (Illumina, San Diego, CA). We first aligned the raw Solexa reads to the reference genome (build 36.3) with MAQ and then rescaled the initial Solexa quality scores to FASTQ format as described in the MAQ's manual http://maq.sourceforge.net/maq- 
Table 2 Summary of Ocular Phenotypes and Next-Generation Sequencing Results in Two Patient Groups

\begin{tabular}{|c|c|c|c|}
\hline Patient & Right and Left Eye Findings & Additional features & $\begin{array}{l}\text { Next generation coding sequence } \\
\text { alterations verified by Sanger sequencing in } \\
\text { this study }\end{array}$ \\
\hline \multicolumn{4}{|l|}{$\underline{\text { ANOP1 }}$} \\
\hline $\begin{array}{l}792- \\
505\end{array}$ & Anophthalmia & - & - \\
\hline $\begin{array}{l}792- \\
508\end{array}$ & Anophthalmia & Feeding disorder & c.313C > T $\rightarrow$ p.Glu105X in OTX2 \\
\hline $\begin{array}{l}792- \\
526\end{array}$ & Anophthalmia & Learning disabilities & - \\
\hline $\begin{array}{l}792- \\
539\end{array}$ & Anophthalmia & Asperger syndrome & - \\
\hline $\begin{array}{l}792- \\
542\end{array}$ & Microphthalmia, coloboma, cyst & - & $\begin{array}{l}\text { c.24C > G } \rightarrow \text { p.Leu8Leu in GDF6 } \\
\text { c.618C }>\mathrm{G}(\mathrm{Hz}) \rightarrow \text { p.Ala206Ala in FOXE3 }\end{array}$ \\
\hline $\begin{array}{l}792- \\
570\end{array}$ & $\begin{array}{l}\text { Anophthalmia/Microphthalmia, microcornea, lens } \\
\text { opacification }\end{array}$ & - & c.601 G > A $\rightarrow$ p.Val201Met in FOXE3 \\
\hline $\begin{array}{l}792- \\
601\end{array}$ & Microphthalmia, chorioretinal colobomas & Hydrocele & - \\
\hline 09-122 & Anophthalmia & - & c.542delC $\rightarrow$ p.Pro181Argfs*22 in SOX2 \\
\hline \multicolumn{4}{|l|}{ ANOP2 } \\
\hline $\begin{array}{l}792- \\
056 \mathrm{~A}\end{array}$ & Microphthalmia & Pervasive developmental disorder & - \\
\hline $\begin{array}{l}792- \\
518\end{array}$ & Microphthalmia & Hamartoma tuber cinereum & $\begin{array}{l}\text { c.124 G > A } \rightarrow \text { p.Glu42Lys in CRYBA4 } \\
\text { [c.70del20 in sOX2] }\end{array}$ \\
\hline $\begin{array}{l}792- \\
530\end{array}$ & Anophthalmia & $\begin{array}{l}\text { Learning disabilities, Arnold-Chiari } \\
\text { malformation }\end{array}$ & - \\
\hline $\begin{array}{l}792- \\
531\end{array}$ & Anophthalmia & - & $\begin{array}{l}\text { c.871 G > A } \rightarrow \text { p.Asp291Asn in VSX2; } \\
\text { [c.67-69dupGGC in SOX2] }\end{array}$ \\
\hline $\begin{array}{l}792- \\
548\end{array}$ & Microphthalmia & - & - \\
\hline $\begin{array}{l}792- \\
563\end{array}$ & Microphthalmia & Arnold-Chiari malformation & c. $720 \mathrm{C}>\mathrm{A}(\mathrm{Hz}) \rightarrow$ p.Cys $240 \mathrm{X}$ in FOXE3 \\
\hline $\begin{array}{l}792- \\
572\end{array}$ & Anophthalmia & Learning disabilities, autistic behavior & c.520 G > A (Hz) $\rightarrow$ p.Ala174Thr in FOXE3 \\
\hline
\end{tabular}

Coding sequence variants only are included and mutations are highlighted in bold; $(\mathrm{Hz})=$ Homozygous sequence alteration; the remainder of the sequence alterations were heterozygous.

man.shtml[21]. We ran MAQ with its default parameters - albeit with a larger outer distance for a correct read pair (-a 500) and a larger threshold on the sum of mismatching base qualities (-e100). We then used the Genome Analysis Toolkit to further rescale the quality scores of the aligned reads to match empirical error rates as described previously (1000 Genome Project Consortium, 2010) [22]. Briefly, bases were binned by original quality score, machine cycle, and neighboring nucleotide; empirical errors rates were assessed for each bin at non-dbSNP sites; and recalibrated quality scores were assigned to each bin to match the empirical error rate. We then ignored bases with recalibrated quality scores below 20 (Q20) and measured coverage at each targeted base to assess experimental completeness.

We then called variants using Syzygy (J. Flannick, manuscript in preparation), a previously described software package designed to call variants in non-indexed pooled groups of samples [23]. Briefly, the goal of variant calling is to distinguish true variation from sequencing errors. This task is harder in the pooled setting than in the single sample setting because the frequency of a single minor allele in the pool $(1 / 2 \mathrm{~N}$, where $\mathrm{N}$ is the number of samples in the pool) can approach the raw error rate of Solexa reads (1\% at Q20 bases). To call a variant at a genomic position, Syzygy compares the likelihood that a variant exists in the pool to the likelihood that all non-reference sequence bases at the position are due to sequencing errors. At positions where the log of the likelihood ratio is above 3, Syzygy calls a variant and then uses an expectation-maximization (EM) algorithm to determine the number of samples in the pool who carry the variant. Syzygy further declares as high-confidence variants that (1) have statistically indistinguishable numbers of non-reference bases on reads from the forward $(+)$ and reverse $(-)$ strands of the genome; (2) have positive log-likelihood ratios based solely on reads from the forward strand and also based 
solely on reads from the reverse strand; and (3) do not occur adjacent to another variant. We used these high confidence variants as our final call set, with all coding variants having likelihood ratio $>3.0$ on both forward and reverse strands.

Coding sequence variants were verified by Sanger sequencing on genomic DNA or whole-genome-amplified (WGA) DNA (GenomePlex Whole Genome Amplification kit; Sigma, St Louis, MO). Sequence variants found in WGA samples were confirmed in genomic DNA to exclude the small possibility of errors induced by the WGA.

\section{Results}

In ANOP1, 13 coding sequence variants were predicted by our method of analysis, 8 of which were listed in the Database of Single Nucleotide Polymorphisms (dbSNP; Table 3). The five predicted sequence variants not in dbSNP were verified by Sanger sequencing as follows: We detected the SOX2 mutation, c.542delC, predicting
p.Pro181Argfs*22, in patient 09-122, our positive control (Figure 1A). However, this mutation was predicted as a deletion at position c.539 (c.539A > D), 3 bp prior to the location of the actual mutation. c.542delC was not included in a comprehensive recent review of SOX2 mutations [7], but the sequence alteration can be presumed to be disease-causing because of likely loss of function, although the deletion occurs after the high mobility group (HMG) domain in the protein. Parental studies were not performed.

We predicted c.313C > T in OTX2, causing p.Gln105X and a premature stop codon just after the homeodomain of the 297 amino acid OTX2 protein (Table 3). This mutation was verified with Sanger sequencing in 792508 (Figure 1B). This mutation is consistent with the loss of function mutations observed in OTX2 in A/M patients [8]. Testing of the healthy parents of this child did not show the same mutation [8].

We verified c.601 G > A, predicting p.Val201Met in FOXE3, in patient 792-570 (Additional File 2 Figure

Table 3 Coding Sequence Variants Predicted by Syzygy and Verified by Sanger Sequencing in the ANOP1 and ANOP2 Libraries

\begin{tabular}{|c|c|c|c|c|c|c|c|}
\hline Gene & Position (hg18) & $\begin{array}{l}\text { Nucleotide } \\
\text { Alteration }^{\mathrm{a}}\end{array}$ & $\begin{array}{l}\text { Predicted Effect on } \\
\text { Protein }\end{array}$ & dbSNP/1000 Genomes & Sanger Sequencing & $\begin{array}{l}\text { Het./ } \\
\text { Homo. }\end{array}$ & Interpretation \\
\hline \multicolumn{8}{|l|}{ ANOP1 } \\
\hline FOXE3 & chr1:47655084 & $c .510 C>T$ & p.Ala170Ala & rs34082359 & Yes; verified & Het. & SNP \\
\hline FOXE3 & chr1:47655175 & c.601 G > A & p.Val201Met & - & Yes; verified ${ }^{10}$ & Het. & SNP \\
\hline FOXE3 & chr1:47655192 & c. $618 \mathrm{C}>\mathrm{G}$ & p.Ala206Ala & - & Yes; verified ${ }^{10}$ & Homo. & SNP \\
\hline SIX3 & chr2:45022837 & $c .90 \mathrm{G}>\mathrm{T}$ & p.Ala30Ala & rs78018362 & Not done & Het. & SNP \\
\hline SIX3 & chr2:45025346 & $c .942 A>G$ & p.Ala314Ala & rs62840660 & Not done & Het. & SNP \\
\hline SOX2 & chr3:182913381 & $c .539 A>D^{c}$ & Predicted FS ${ }^{d}$ & - & Yes; c.542delC verified & Het. & Mutation \\
\hline GDF6 & chr8:97242073 & c. $24 \mathrm{C}>\mathrm{G}$ & p.Leu8Leu & - & Yes, verified & Het. & Unknown \\
\hline PAX2 & chr10:102558862 & c.867C > T & p.Asn289Asn & rs1800897 & Not done & Het. & SNP \\
\hline PAX2 & chr10:102558973 & C.978A > C & p.Pro326Pro & rs1800898 & Not done & Het. & SNP \\
\hline BMP4 & chr14:53487272 & c. $455 \mathrm{~T}>\mathrm{C}$ & p.Val152Ala & rs17563 & Not done & Het. & SNP \\
\hline OTX2 & chr14:56338763 & c. $313 C>T$ & p.Glu105X & - & Yes; verified $^{8}$ & Het. & Mutation \\
\hline VSX2 & chr14:73781636 & $c .471 \mathrm{C}>\mathrm{T}$ & p.Ser157Ser & rs35435463 & Not done & Het. & SNP \\
\hline CRYBA4 & chr22:25351457 & c. $171 \mathrm{C}>\mathrm{T}$ & p.Phe57Phe & rs5761637 & Not done & Het. & SNP \\
\hline \multicolumn{8}{|l|}{ ANOP2 } \\
\hline$\overline{F O X E 3}$ & chr1:47655084 & $c .510 C>T$ & p.Ala170Ala & rs34082359 & Yes; verified & Het. & SNP \\
\hline FOXE3 & chr1:47655294 & c. $720 \mathrm{C}>\mathrm{A}$ & p.Cys240X & - & YES; verified ${ }^{10}$ & Homo. & Mutation \\
\hline SIX3 & chr2:45023323 & $c .576 C>T$ & p.Arg192Arg & rs182881 & Not done & Het. & SNP \\
\hline PAX2 & chr10:102558862 & $\mathrm{C} .867 \mathrm{C}>\mathrm{T}$ & p.Asn289Asn & rs1800897 & Not done & Het. & SNP \\
\hline PAX2 & chr10:102558973 & C.978A > C & p.Pro326Pro & rs1800898 & Not done & Het. & SNP \\
\hline PAX6 & chr11:31768060 & c. $1268 \mathrm{~A}>\mathrm{T}$ & $\begin{array}{l}\text { p.X423Leu } \\
\text { extX*15 }\end{array}$ & - & YES; not verified ${ }^{24}$ & Het. & Mutation \\
\hline BMP4 & chr14:53487272 & c.455T > C & p.Val152Ala & rs17563 & Not done & Het. & SNP \\
\hline VSX2 & chr14:73781636 & $c .471 C>T$ & p.Ser157Ser & rs35435463 & Not done & Het. & SNP \\
\hline VSX2 & chr14:73797160 & c.871 G > A & p.Asp291Asn & rs75395981 & YES; verified & Het. & SNP \\
\hline CRYBA4 & chr22:25349282 & c.124 G > A & p.Glu42Lys & - & YES; verified & Het. & Unknown \\
\hline CRYBA4 & chr22:25351457 & C. $171 \mathrm{~T}>\mathrm{C}$ & p.Phe57Phe & rs5761637 & Not done & Het. & SNP \\
\hline
\end{tabular}

${ }^{a}$ Nucleotide numbering is according to dbSNP (Database of Single Nucleotide Polymorphisms; http://www.ncbi.nlm.nih.gov/projects/SNP/). Het./Homo. ${ }^{b}=$ heterozygous or homozygous sequence alteration; $D^{c}=$ predicted deletion; $F S^{d}=$ frameshift. 


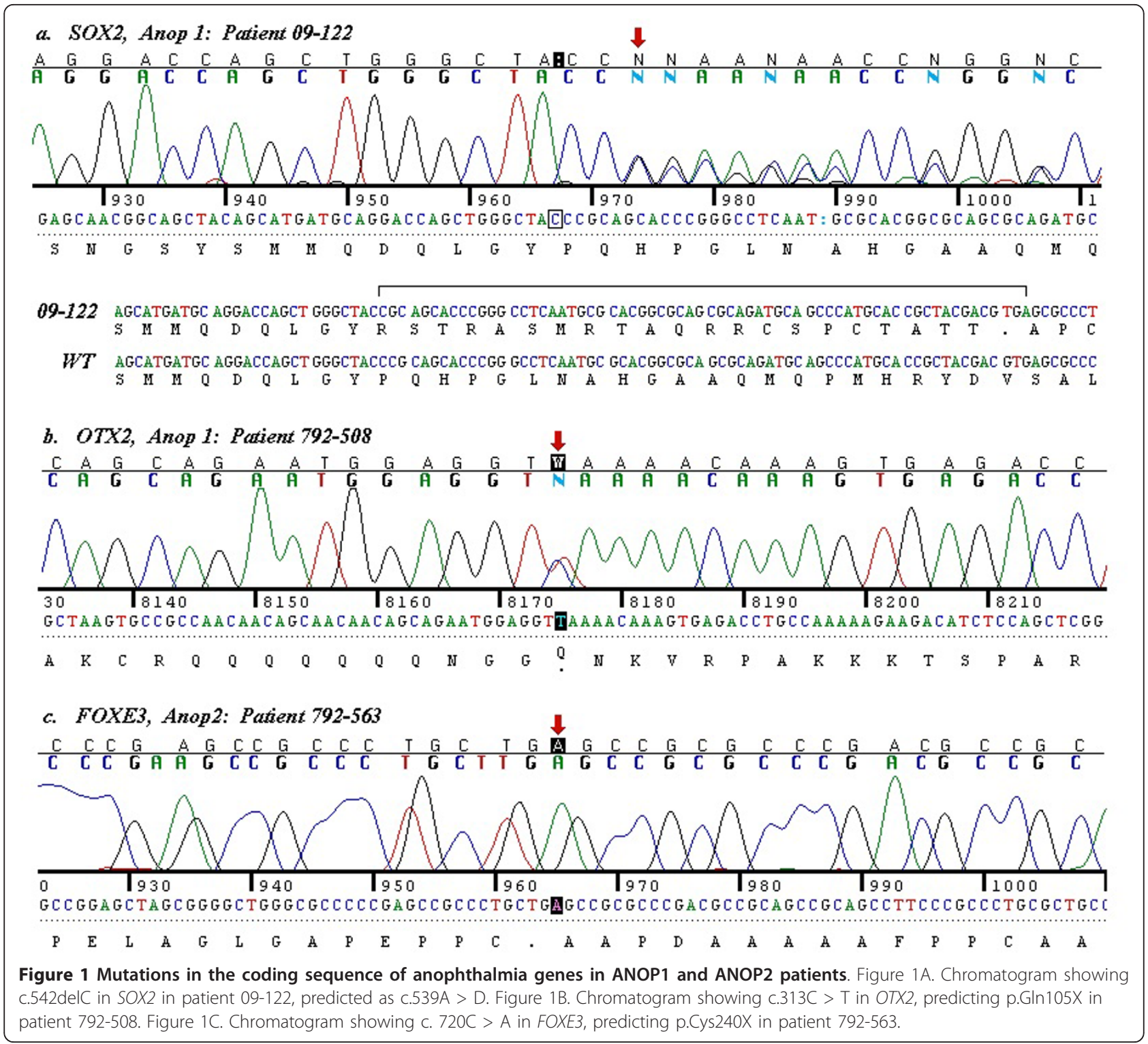

S1Ai) and a normal parent (Additional File 2 Figure S1Aii). This SNP has not yet been included in public databases, but has previously been reported in both A/ $\mathrm{M}$ patients and normal controls and is likely to be a polymorphism [10]. We verified c.618C $>\mathrm{G}$, a synonymous alteration resulting in p.Ala206Ala in FOXE3, in patient 792-542, who was homozygous for this SNP (Additional File 2, Figure S1B). The SNP has previously been described in both $\mathrm{A} / \mathrm{M}$ patients and controls [10]. Finally, we verified c.24C > G, predicting a synonymous alteration, p.Leu8Leu in GDF6, in patient 792-542 (Additional File 2, Figure S1C). This novel, synonymous sequence alteration was not predicted to have a significant effect on splicing (Automated Splice Site Analysis; https://splice.uwo.ca). Its significance is therefore uncertain, although it is most likely to be a SNP, as it is present in a low frequency $(1 / 10,755$ alleles in the Caucasian and African-American populations) in the Exome Variant Server http://evs.gs.washington.edu/EVS/. We were unable to obtain parental samples.

In ANOP2, 12 coding sequence variants were predicted, of which 9 had been documented in dbSNP or the 1000 genomes database (http://www.1000genomes. org/; Table 3). From the 3 sequence alterations that were not in public databases, we verified c.720C > A, predicting p.Cys240X in FOXE3 by Sanger sequencing in patient 792-563 (Figure 1C). The patient was homozygous for this published mutation, consistent with the autosomal recessive inheritance described with FOXE3 mutations [10]. 
We verified c.871 G > A, resulting in p.Asp291Asn, in VSX2 in patient 792-531 (Additional File 2, Figure S1D). This sequence variant is a SNP present in the 1000 genomes database and in dbSNP. We also verified c.124 G $>\mathrm{A}$, resulting in p.Glu42Lys in CRYBA4, in patient 792518 (Additional File 1, Figure S1E). Sequencing of 90 control chromosomes was normal for this sequence variant (data not shown) and Polyphen-2 http://genetics. bwh.harvard.edu/pph2/ predicted that the alteration was 'possibly damaging', although the position-specific independent counts (PSIC) score was low at 0.438. Parental samples were unavailable and the significance of this sequence variant is not known, although it is likely to be a SNP as the same patient has a pathogenic deletion in SOX2. Finally, we predicted c.1268A > T, resulting in p.X423LeuextX*15, a previously described 'run-through' mutation in PAX6 [24]. However, we did not verify this sequence change using a forward primer (Additional file 3 , Figure S2) and the polyA tail from the PAX6 gene prevented sequencing in the reverse direction. This was the only predicted missense alteration that we were unable to confirm.

In ANOP2, patient 792-531 was known to have a three base pair insertion in SOX2, c.67-69dupGGC, predicting the insertion of an additional glycine residue at residue 24 after a stretch of five glycine residues at amino acids 19-23 in the wildtype protein (data not shown). Patient 792-518 was also found to have the common SOX2 deletion, c.70del20, resulting in p. Asn $24 \mathrm{fs} * 88$ and premature protein truncation during the course of this work [9]. Neither of these mutations was predicted when we used high likelihood scores in both the forward and the reverse strands at the same base for mutation prediction (data not shown). This methodology would not have detected larger deletions or insertions, as one strand could still contain normal sequence at the base involved in the mutation, depending on the size of the abnormality. We therefore re-checked all of the predictions for deletions and insertions that had a likelihood ratio > 3.0 in either the forward or the reverse strand for SOX2 and found that both an insertion and deletion were predicted at nucleotide c.57 G (data not shown). Although this prediction was not precisely at the position of c.67-69dupGGC or c.70del20, Sanger sequencing of this region in the ANOP2 patients would have lead to the verification of the duplication in patient 792-531 and the deletion in patient 792-518 (data not shown). It should also be noted that we used short reads and that a $20 \mathrm{bp}$ deletion in the read size may result in insufficient homology for a read to be accurately mapped to the reference genome. We conclude that our analysis was highly effective for the detection of missense alterations, but less efficient for deletions and duplications, particularly those of a larger size. Our analysis did not predict any large copy number variants (data not shown).

Coverage for the ANOP1 library was high, with 100\% of coding sequence of the 9 genes at $>160 \mathrm{X}$ coverage (i. e. $>20 \mathrm{X}$ for 8 samples) except for exon 6 of PAX2, which was not covered by the library (Additional file 1, Table S2). For ANOP2, there was 100\% coverage for the coding exons of 8 genes at $>140 \mathrm{X}$ (i.e. $>20 \mathrm{X}$ for 7 samples). Exon 6 of PAX2 was not covered and FOXE3 (78.7\% > 140X coverage) and SIX3 $(96.9 \%>140 \mathrm{X}$ coverage; Additional file 1, Table $S 2$ ) had reduced coverage for some regions in the ANOP2 library. It is unclear if the reduced coverage has resulted in false negative results. We did detect homozygosity for c.520 G > A, predicting p.Ala174Thr in FOXE3, by Sanger sequencing in patient 792-572 whilst sequencing to verify c.720C > A in FOXE3 (Table 2; data not shown). The c.520 G > A sequence alteration was novel and was not predicted with the high threshold parameters used, but was deemed likely to be benign by Polyphen-2, with a PSIC score of 0.025 (data not shown).

\section{Discussion}

We were able to use next-generation sequencing to screen multiple pathogenic genes efficiently in a cohort of $15 \mathrm{~A} / \mathrm{M}$ patients and were able to identify diseasecausing mutations in three patients: c.542delC, predicting p.Pro181Argfs*22 in SOX2 (positive control), c.313C $>\mathrm{T}$ in OTX2, predicting p.Gln105X, and c.720C > A, predicting p.Cys240X, in FOXE3. All of these alterations are consistent with loss of function and are considered to be pathogenic. We retrospectively identified a known duplication and deletion in SOX2 in two further patients using our analysis method with altered parameters that required a high likelihood score in one strand only (data not shown), but the basepair at which the sequence alteration was predicted was not an exact match to the aberrations found by Sanger sequencing. We did not find mutations in the other 10 patients, although our screening was incomplete in that the GDF6 gene was not covered in the ANOP1 library and neither library covered $R A X$. However, our studies emphasize the genetic heterogeneity of $\mathrm{A} / \mathrm{M}$, the rarity of mutations in some of the known pathogenic genes and the need for further gene discovery.

We encountered several difficulties with our next-generation sequencing methodology. We chose not to barcode our samples to simplify library preparation, but our lack of bar-coding to distinguish between different samples increased the number of patients in whom Sanger sequencing was needed. Using bar-coding would have simplified our analysis. We identified relatively few novel coding variants that required Sanger sequencing using Syzygy as our analysis tool, which was a strength 
of the analysis methodology, and we accepted the prediction of previously reported SNPs as likely to be correct. The error rate of massively parallel sequencing has been estimated to be high, at $0.5 \%$ per base call [25]. A high false positive rate is more likely when pooling samples and with low expected frequencies of variant detection, and less likely with increased depth of coverage and paired-end reads [25]. In a recent study, only 74 out of 114 predicted mutations or sequence variants (65\%) were confirmed with Sanger sequencing [25]. In our much smaller study, we confirmed $8 / 9$ predicted variants (87.5\%).

One of the predicted mutations from our next-generation sequencing, c.1268A $>\mathrm{T}$, resulting in $\mathrm{p}$. X423LeuextX*15 in PAX6 is especially noteworthy. This mutation has previously been described in four patients with aniridia, without mention of A/M (PAX6 homepage; Leiden Open Variation Database; http://lsdb.hgu. mrc.ac.uk/home.php?select_db=PAX6). The mutation results in an alteration to the normal stop codon, resulting in 'run-through' and a later stop after a further 15 amino acids. It was surprising to us that a mutation for an eye malformation, albeit one distinct from $\mathrm{A} / \mathrm{M}$, would be predicted but not verified despite high coverage in that region and the possibility of a low level of mosaicism not detectable by Sanger sequencing cannot be excluded.

\section{Conclusion}

We used next-generation sequencing with a pooled approach to sequence 9 known causative genes in $15 \mathrm{~A} /$ $M$ patients. We were successful in identifying three mutations - c.542delC in SOX2, resulting in p. Pro181Argfs $* 22$, p.Glu105X in OTX2 and p.Cys240X in FOXE3. Our analysis methodology resulted in one false positive $P A X 6$ mutation that was not verified by Sanger sequencing; we were also unable to detect a small deletion of $20 \mathrm{bp}$ and a duplication of $3 \mathrm{bp}$, both in SOX2. Next-generation sequencing with pooled samples enabled rapid screening of candidate genes for $\mathrm{A} / \mathrm{M}$ and efficient detection of missense mutations; however, we were less successful in finding small intragenic deletions and duplications.

\section{Additional material}

Additional file 1: Table S1. Amplified Fragments and Primers for Anophthalmia/Microphthalmia Genes. Table S2. Summary of Coverage for Coding Sequence of Anophthalmia/Microphthalmia Genes in ANOP1 and ANOP2 Libraries

Additional file 2: Figure S1. Single Nucleotide Polymorphisms (SNPS) and Sequence Alterations of Uncertain Significance in Anophthalmia Genes in the ANOP1 and ANOP2 Libraries. Figure S1A. Chromatogram showing c.601 G > A, predicting p.Val201Met in FOXE3 in (i) patient, 792570, and (ii) parent, 792-569. Figure S1B. Chromatogram showing C.618C
$>$ G, predicting p.Ala206Ala, in FOXE3 in patient 792-542. Figure S1C. Chromatogram showing c.24C > G, predicting p.Leu8Leu, in GDF6 in patient 792-542. Figure S1D. Chromatogram showing c.871 G>A, predicting p.Asp291Asn, in VSX2 in patient 792-531. Figure S1E. Chromatogram showing C.124 G > A, predicting p.Glu42Lys, in CRYBA4, in patient 792-518.

Additional file 3: Figure S2. Predicted coding sequence variants in ANOP1 and ANOP2 patients that were not verified by Sanger sequencing. Figure S2. Chromatograms showing normal sequence at c.1268A > T, predicting p.X423LeuextX*15 in PAX6, in patients from ANOP2.

\section{Acknowledgements}

Anne Slavotinek was funded by a K08 grant, K08HD053476-01A1, from The Eunice Kennedy Shriver National Institute of Child Health, National Institutes of Health.

\section{Author details}

${ }^{1}$ Department of Pediatrics, Division of Genetics, University of California, San Francisco, 533 Parnassus St, Room U585P, San Francisco CA 94143-0748 USA. ${ }^{2}$ Broad Institute of Harvard and MIT, Cambridge MA Massachusetts General Hospital, Boston, Massachusetts USA. ${ }^{3}$ Department of Neurology, University of California, San Francisco, San Francisco, California 94143-0114 USA. ${ }^{4}$ Division of Genetics, Department of Pediatrics, Albert Einstein Medical Center, Philadelphia, Pennsylvania 19141 USA. ${ }^{5}$ Vincent J. Coates Genomics Sequencing Laboratory (GSL) QB3/University of California, Berkeley USA B206 Stanley Hall MC 3220 Berkeley, CA 94720-3220.

\section{Authors' contributions}

NL: performed experimental work with PCR and prepared fragments for next-generation sequencing.

JF: performed bioinformatics analysis of results from targeted nextgeneration sequencing.

MY: performed PCR to verify predicted sequence alterations from Syzygy. $\mathrm{J}$ : gave advice and experimental help regarding sample preparation for next-generation sequencing.

TB/AS: contributed samples for sequencing

LT: Sequenced samples with Illumina platform.

EHS: contributed reagents and advice regarding next-generation sequencing AMS: experimental design, help with sequencing and analysis of results; wrote the paper

All authors read and approved the final version of the manuscript.

\section{Competing interests}

The authors declare that they have no competing interests.

Received: 11 October 2011 Accepted: 28 December 2011

Published: 28 December 2011

\section{References}

1. Shah SP, Taylor A, Sowden JC, Ragge NK, Russell-Eggitt I, Rahi JS, Gilbert CE, Surveillance of Eye Anomalies (SEA-UK) Special Interest Group: Anophthalmos, microphthalmos and typical coloboma in the UK: a prospective study of incidence and risk. Invest Ophthalmol Vis Sci 2011, 52:558-564.

2. Ragge NK, Lorenz B, Schneider A, Bushby K, de Sanctis L, de Sanctis U, Salt A, Collin JR, Vivian AJ, Free SL, Thompson P, Williamson KA, Sisodiya SM, van Heyningen V, Fitzpatrick DR: SOX2 anophthalmia syndrome. Am J Med Genet A 2005, 135:1-7.

3. Reis LM, Tyler RC, Schneider A, Bardakjian T, Semina EV: Examination of SOX2 in variable ocular conditions identifies a recurrent deletion in microphthalmia and lack of mutations in other phenotypes. Mol Vis 2010, 16:768-773.

4. Verma AS, Fitzpatrick DR: Anophthalmia and microphthalmia. Orphanet $J$ Rare Dis 2007, 2:47.

5. Gonzalez-Rodriguez J, Pelcastre EL, Garcia-Ortiz JE, Amato-Almanza M, Villanueva-Mendoza C, Espinosa-Mattar Z, Zenteno JC: Mutational screening of CHX10, GDF6, OTX2, RAX and SOX2 genes in 50 unrelated 
microphthalmia-anophthalmia-coloboma (MAC) spectrum cases. $\mathrm{Br} J$ Ophthalmol 2010, 94:1100-1104.

6. Fantes J, Ragge NK, Lynch SA, McGill NI, Collin JR, Howard-Peebles PN, Hayward C, Vivian AJ, Williamson K, van Heyningen V, FitzPatrick DR Mutations in SOX2 cause anophthalmia. Nat Genet 2003, 33:461-463

7. Schneider A, Bardakjian T, Reis LM, Tyler RC, Semina EV: Novel SOX2 mutations and genotype-phenotype correlation in anophthalmia and microphthalmia. Am J Med Genet A 2009, , 149A: 2706-2715.

8. Schilter KF, Schneider A, Bardakjian T, Soucy JF, Tyler RC, Reis LM, Semina EV: OTX2 microphthalmia syndrome: four novel mutations and delineation of a phenotype. Clin Genet 2010, , 79: 158-168.

9. Percin EF, Ploder LA, Yu JJ, Arici K, Horsford DJ, Rutherford A, Bapat B, Cox DW, Duncan AMV, Kalnins VI, Kocak-Altintas A, Sowden JC, Trabousli E, Sarfarazi M, Mclnnes RR: Human microphthalmia associated with mutations in the retinal homeobox gene CHX10. Nat Genet 2000, 25:397-401.

10. Reis LM, Tyler RC, Schneider A, Bardakjian T, Stoler JM, Melancon SB, Semina EV: FOXE3 plays a significant role in autosomal recessive microphthalmia. Am J Med Genet A 2010, , 152A: 582-590.

11. Billingsley G, Santhiya ST, Paterson AD, Ogata K, Wodak S, Hosseini SM, Manisastry SM, Vijayalakshmi P, Gopinath PM, Graw J, Héon E: CRYBA4, a novel human cataract gene, is also involved in microphthalmia. Am J Hum Genet 2006, 79:702-709.

12. Amiel J, Audollent S, Joly D, Dureau P, Salomon R, Tellier AL, Augé J, Bouissou F, Antignac C, Gubler MC, Eccles MR, Munnich A, Vekemans M, Lyonnet S, Attié-Bitach T: PAX2 mutations in renal-coloboma syndrome: mutational hotspot and germline mosaicism. Eur J Hum Genet 2000, 8:820-826

13. Glaser T, Jepeal L, Edwards JG, Young SR, Favor J, Maas RL: PAX6 gene dosage effect in a family with congenital cataracts, aniridia, anophthalmia and central nervous system defects. Nat Genet 1994, 7:463-471.

14. Bardakjian T, Weiss A, Schneider AS: Anophthalmia/Microphthalmia Overview. In GeneReviews [Internet], Seattle (WA). Edited by: Pagon RA, Bird TC, Dolan CR, Stephens K. University of Washington, Seattle; 1993-2004; Jan 29 [updated 2007 Feb 15].

15. Bakrania P, Efthymiou M, Klein JC, Salt A, Bunyan DJ, Wyatt A, Ponting CP, Martin A, Williams S, Lindley V, Gilmore J, Restori M, Robson AG, Neveu MM, Holder GE, Collin JR, Robinson DO, Farndon P, Johansen-Berg H, Gerrelli D, Ragge NK: Mutations in BMP4 cause eye, brain, and digit developmental anomalies: overlap between the BMP4 and hedgehog signaling pathways. Am J Hum Genet 2008, 82:304-319.

16. ten Bosch JR, Grody WW: Keeping up with the next-generation: massively parallel sequencing in clinical diagnostics. J Mol Diagn 2008, 10:484-492.

17. Ng SB, Buckingham KJ, Lee C, Bigham AW, Tabor HK, Dent KM, Huff CD, Shannon PT, Jabs EW, Nickerson DA, Shendure J, Bamshad MJ: Exome sequencing identifies the cause of a mendelian disorder. Nat Genet 2010, 42:30-35.

18. Ng SB, Bigham AW, Buckingham KJ, Hannibal MC, McMillin MJ, Gildersleeve HI, Beck AE, Tabor HK, Cooper GM, Mefford HC, Lee C, Turner EH, Smith JD, Rieder MJ, Yoshiura K, Matsumoto N, Ohta T, Niikawa N, Nickerson DA, Bamshad MJ, Shendure J: Exome sequencing identifies MLL2 mutations as a cause of Kabuki syndrome. Nat Genet 2010, 42:790-793.

19. Choi M, Scholl UI, Ji W, Liu T, Tikhonova IR, Zumbo P, Nayir A, Bakkaloğlu A, Ozen S, Sanjad S, Nelson-Williams C, Farhi A, Mane S, Lifton RP: Genetic diagnosis by whole exome capture and massively parallel DNA sequencing. Proc Natl Acad Sci USA 2009, 106:19096-190101.

20. Lalonde E, Albrecht S, Ha KC, Jacob K, Bolduc N, Polychronakos C, Dechelotte P, Majewski J, Jabado N: Unexpected allelic heterogeneity and spectrum of mutations in Fowler syndrome revealed by next-generation exome sequencing. Hum Mutat 2010, 31:918-923.

21. Li H, Ruan J, Durbin R: Mapping short DNA sequencing reads and calling variants using mapping quality scores. Genome Res 2008, 18:1851-1858.

22. McKenna A, Hanna M, Banks E, Sivachenko A, Cibulskis K, Kernytsky A, Garimella K, Altshuler D, Gabriel S, Daly M, DePristo MA: The Genome Analysis Toolkit: a MapReduce framework for analyzing next-generation DNA sequencing data. Genome Res 2010, 20:1297-1303.

23. Calvo SE, Tucker EJ, Compton AG, Kirby DM, Crawford G, Burtt NP, Rivas M, Guiducci C, Bruno DL, Goldberger OA, Redman MC, Wiltshire E, Wilson CJ, Altshuler D, Gabriel SB, Daly MJ, Thorburn DR, Mootha VK: High- throughput, pooled sequencing identifies mutations in NUBPL and FOXRED1 in human complex I deficiency. Nat Genet 2010, 42:851-858.

24. Tzoulaki I, White IM, Hanson IM: PAX6 mutations: genotype-phenotype correlations. BMC Genet 2005, 6:27.

25. Otto EA, Ramaswami G, Janssen $S$, Chaki M, Allen SJ, Zhou W, Airik R, Hurd TW, Ghosh AK, Wolf MT, Hoppe B, Neuhaus TJ, Bockenhauer D, Milford DV, Soliman NA, Antignac C, Saunier S, Johnson CA, Hildebrandt F, GPN Study Group: Mutation analysis of 18 nephronophthisis associated ciliopathy disease genes using a DNA pooling and next-generation sequencing strategy. J Med Genet 2010, 52:105-116.

\section{Pre-publication history}

The pre-publication history for this paper can be accessed here: http://www.biomedcentral.com/1471-2350/12/172/prepub

doi:10.1186/1471-2350-12-172

Cite this article as: Lopez Jimenez et al:: Targeted 'Next-Generation' sequencing in anophthalmia and microphthalmia patients confirms SOX2, OTX2 and FOXE3 mutations. BMC Medical Genetics 2011 12:172.

\section{Submit your next manuscript to BioMed Central and take full advantage of:}

- Convenient online submission

- Thorough peer review

- No space constraints or color figure charges

- Immediate publication on acceptance

- Inclusion in PubMed, CAS, Scopus and Google Scholar

- Research which is freely available for redistribution

Submit your manuscript at www.biomedcentral.com/submit
Biomed Central 